\title{
Identification of dendritic cells in the blood and synovial fluid of children with Juvenile Idiopathic Arthritis
}

\author{
Jacek Tabarkiewicz ${ }^{1,}$ Jacek Postępski $^{2}$, Edyta Olesińska², Jacek Roliński ${ }^{1}$, \\ Ewa Tuszkiewicz-Misztal ${ }^{2}$ \\ ${ }^{1}$ Department of Clinical Immunology, Medical University of Lublin, Poland \\ ${ }^{2}$ Department of Pediatrics, Lung Diseases and Rheumatology, Medical University of Lublin, Poland
}

\begin{abstract}
Childhood chronic arthritis of unknown etiology is known collectively as juvenile idiopathic arthritis (JIA) and consists of heterogeneous subtypes with unique clinical patterns of disease. JIA is the commonest rheumatic disease in children and may still result in significant disability, with joint deformity, growth impairment, and persistence of active arthritis into adulthood. Basic research is rather focused on rheumatoid arthritis, and this lead to small number of publications considering JIA. In this study we examine, by flow cytometry, the expression of dendritic cells (DCs) in the peripheral blood and synovial fluid of children with active JIA in a group of 220 patients. We reveal a significant decrease in the percentage of immature DCs in the blood of patients compared to control children. Surprisingly, we found higher percentages of mature circulating dendritic cells. Both populations of DCs, immature and mature, were accumulated in patients' synovial fluid. We also confirmed the presence of $\mathrm{CD} 206^{+} / \mathrm{CD} 209^{+}$in JIA samples, which can represent a population of macrophages with dendritic cells morphology. Our results support the thesis that dendritic cells are crucial in the induction and maintenance of autoimmune response and local inflammation during juvenile idiopathic arthritis. (Folia Histochemica et Cytobiologica 2011; Vol. 49, No. 1, pp. 188-199)
\end{abstract}

Key words: dendritic cells, CD1c, CD303, CD83, CD206, CD209, arthritis, JIA

\section{Introduction}

A combination of genetic and environmental factors predisposes to the development of autoimmune reaction. Stimulation of autoreactive lymphocytes by professional antigen presenting cells (APCs) is crucial for the beginning of a vicious circle of reactions leading to the destruction of tissues and organs. Basic experiments and animal models show that dendritic cells' (DCs) immunostimulatory functions and dysregulation of tolerogenic properties play a pivotal role in the pathogenesis of arthritis $[1,2]$.

Correspondence address: J. Tabarkiewicz,

Department of Clinical Immunology,

Medical University of Lublin,

Jaczewskiego Str. 8, 20-097 Lublin, Poland;

e-mail: jacek.tabarkiewicz@gmail.com
Dendritic cells comprise a complex network of multifarious antigen presenting cells that are important not only to the orchestration of active immune response, but also to the maintenance of both central and peripheral tolerance. It is well-known that DCs do not represent a homogenous cell population, but are a mixture of at least two populations: myeloid and lymphoid dendritic cells, which vary in tissue distribution, morphology, function, and immunophenotype [3, 4]. Immature myeloid dendritic cells (mDCs) are of monocytoid morphology and express myeloid markers such as: CD13, CD33 and CD11c antigen. Myeloid immature dendritic cells also express characteristic antigens such as BDCA-1 (CD1c) or BDCA-3 [4]. Plasmocytoid DCs (pDCs) are CD4 and $\mathrm{CD} 123$ positive, CD11c negative, and express neither myeloid lineage markers such as CD13 or $\mathrm{CD} 33$, nor Fc receptors. These cells also express relatively lower levels of HLA-DR and HLA-DQ. Circu- 
lating plasmacytoid dendritic cells express characteristic antigen BDCA-2 (CD303) or BDCA-4 (CD304) [4].

The expression of surface molecules on DCs is dynamic and changes according to tissue localization and maturation state. Most of the immature DCs are characterized by expression of molecules associated with antigen uptake. On the other hand, mature DCs lose their capacity for antigen engulfment, and acquire molecules necessary for stimulation of $\mathrm{T}$ lymphocytes e.g. CD83, CD80, and CD86 [3].

The role of dendritic cells in the pathogenesis and the clinical course of disease, as well as in the therapy of rheumatoid arthritis has been intensively investigated and was reviewed by Lebre and Ruttela [1, 2, 5]. Unfortunately, as yet, insufficient work has focused on the function and dysfunction of DCs in juvenile idiopathic arthritis (JIA).

According to the International League of Associations for Rheumatology, the term 'juvenile idiopathic arthritis' comprises a heterogeneous group of chronic disease subtypes that are characterized by arthritis beginning before the age of 16 with symptoms persisting for more than six weeks $[6,7]$. The etiology of JIA is still poorly understood, despite it being the commonest autoimmune disease in children. Although new therapeutic approaches have been identified, many children still suffer severe long-term disability. According to the type of onset of disease, juvenile idiopathic arthritis has been classified into homogenous subtypes for a better understanding of its epidemiology and pathogenesis, as well as for improvement in quality of multicenter clinical studies $[6,7]$. Oligoarthritis and polyarthritis are the prevalent subtypes of JIA and comprise most cases. Next most common are other categories of JIA like: enthesitis-related arthritis, psoriatic arthritis, systemic arthritis and undifferentiated arthritis [7]. A combination of environmental and immunologic factors (e.g. infections) and a certain genetic (e.g. specific HLA allels) susceptibility may contribute to this disorder. Since there is no pathognomic finding for this group of arthritis, diagnosis is based on the combined evaluation of anamnesis, clinical presentation and, to some extent, laboratory abnormalities.

The aim of our study was to examine the expression of different DCs' markers in the peripheral blood and inflammatory synovial fluid during JIA exacerbation and to compare these findings to the same populations of DCs in the blood of healthy children and non-inflammatory synovial fluid. To the best of our knowledge, this is the first large cohort study describing immature and mature dendritic cells in the blood and synovial fluid of patients with JIA.

\section{Material and methods}

\section{Patients and controls}

220 patients who fulfilled ILAR criteria for JIA (Edmonton, 2001) and were treated in the Department of Pediatrics, Lung Diseases and Rheumatology, Medical University of Lublin between 2001 and 2009 were included in the study. Of these, all provided peripheral blood (PB) samples and 52 (none with systemic JIA) also provided synovial fluid (SF) samples. Of the 220 children who suffered from JIA, $55 \%$ were diagnosed with oligoarticular onset, $25 \%$ polyarticular onset, $5 \%$ systemic onset and $15 \%$ enthesitis-related arthritis. The age of the patients ranged from one to 19 years (mean $11.26 \pm 4.6$ ) and $68.1 \%$ of them were girls. All samples were collected during the acute phase of the disease. Peripheral blood was taken during blood collection for diagnostic procedures, and synovial fluid was collected during therapeutic puncture of the knee joint. Fifty control children provided PB samples during examination before minor surgery and were enrolled into the control group after exclusion of any disease except minor injury. In addition, we examined samples of post-traumatic non-inflammatory synovial fluid from 20 adult patients subjected to orthopedic surgery after injury of knees' ligaments. The study was approved by the Bioethics Committee of the Medical University of Lublin, and all statutory guardians of juvenile patients gave their informed consent for the study. Those aged over 16 gave their own informed consent.

\section{Isolation of the peripheral blood and synovial fluid mononuclear cells}

Peripheral blood and synovial fluid were collected in sterile heparinized tubes. Mononuclear cells were separated by gradient centrifugation over Gradisol-L (Aqua Medica, Poland) and washed twice in PBS (phosphate buffered saline) (PAA, Austria) without $\mathrm{Ca}^{2+}$ and $\mathrm{Mg}^{2+}$, containing $0.5 \%$ BSA (bovine serum albumin) (Sigma, Germany) and 2 mM EDTA (Sigma-Aldrich, Germany).

\section{Immunophenotyping of the cells}

The cell surface antigens in each case were determined on fresh cells at the time of sample submission. The following directly conjugated monoclonal antibodies were used: mouse anti-human BDCA-1 (CD1c)-FITC (Miltenyi-Biotec, Germany), BDCA-2 (CD303)-FITC (Miltenyi-Biotec, Germany), CD123-PE (Becton Dickinson, USA), CD19-PE-Cy5 (BD 
Pharmingen, USA). For the estimation of DCs maturation and function marker, we used the following combinations of antibodies: anti-CD83 FITC/anti-CD1a PE/anti-HLA-DR PE-Cy5, anti-CD80 FITC/ /anti-CD86 PE/anti-HLA-DR PE-Cy5 and CD209 FITC/CD206 PE/anti-HLA-DR PE-Cy5, all of them from BD Pharmingen, USA. Immunofluorescent staining was prepared according to manufacturers' protocols. Class matched isotype control was used to establish unspecific binding. Cells were collected using a three-color FACSCalibur flow cytometer equipped with 488-nm argon laser (Becton Dickinson, USA) and analyzed with CellQuest and FlowJo 7.5 software. We collected 300,000 total events. Cell debris and dead cells were excluded from the analysis based on scatter signals and PI staining. The mononuclear cell analysis region was analyzed for CD1c and CD 19 staining. CD $1 \mathrm{c}^{+} \mathrm{B}$ cells were excluded from $\mathrm{CD} 1 \mathrm{c}^{+}$blood dendritic cells by counter-staining for CD19. $\mathrm{CD} \mathrm{c}^{+} / \mathrm{CD} 19^{-}$cells were counted as immature myeloid DCs. Next, the mononuclear cell analysis region was analyzed for CD303 and CD123 antigens. $\mathrm{CD} 03^{+} / \mathrm{CD} 123^{+}$cells are counted as immature plasmacytoid DCs. Representative sample analysis is shown in Figures 1 and 2. Results are expressed as percentage of the cells in mononuclear cells gate.

\section{Statistical analysis}

Kruskal Wallis ANOVA, U-Mann-Whitney and Wilcoxon non-parametric tests and Statistica 9 PL software were applied to statistical analysis. All results are showed as medians and interquartile range (IQR).

\section{Results}

\section{$\mathrm{CD}^{+} \mathrm{c}^{+}$myeloid and $\mathrm{CD303}^{+}$plasmacytoid dendritic cells in peripheral blood and inflammatory synovial fluid in children with JIA}

We evaluated the percentages of myeloid and plasmacytoid subpopulation of DCs as well as the relation between these cells and the total percentage of immature dendritic cells. It is well known that myeloid and lymphoid dendritic cells differ in cytokines profile and function, so we believe that balance between these two populations is one of the crucial points in immune response. In children with JIA, we found a statistically significant $(p=0.000000001)$ higher percentage of immature myeloid DCs in SF $(3.47 \%$; 3.55) than in the peripheral blood $(0.43 \%$; 0.31$)$ (Figure 3$)$. The percentage of immature plasmacytoid dendritic cells was also significantly $(\mathrm{p}=0.00000001)$ higher in inflammatory SF $(0.84 \% ; 1.56)$ than in PB $(0.35 \%$; 0.37$)$ (Figure 3). The increased percentages in SF of both subpopulations of immature DCs result in a significantly ( $p=0.000000001)$ higher total percentage of immature DCs in SF $(5.13 \%$; 4.08) than in $\mathrm{PB}(0.79 \%$; 0.61 ) (Figure 3). We also concluded that in inflammatory SF of children with JIA, myeloid immature dendritic cells are in the majority. Myeloid/plasmacytoid DCs ratio in SF was 4.58; 6.95 and it was significantly $(\mathrm{p}=0.00003)$ higher than in PB $(1.2 ; 1.30)$.

\section{Differences in immature DCs percentages between JIA subtypes}

Using a Kruskal Wallis test we found that groups representing diverse categories of JIA significantly $(\mathrm{H}=8.36, \mathrm{p}=0.04)$ differ in percentages of CD1c ${ }^{+}$dendritic cells (Figure 4). We concluded that patients with systemic JIA have the lowest percentages of myeloid DCs $0.16 \%(0.26)$ and paired U Mann-Whitney tests showed significant differences when compared to other types of JIA: polyarticular $(\mathrm{p}=0.01)$, oligoarticular (0.004) and enthesitis-related arthritis $(\mathrm{p}=0.01)$ onset. We did not find any significant differences in other examined parameters. However, the percentage of pDCs in systemic JIA was about twice lower that in the other subtypes of JIA, and almost a four times that in the control group. Detailed results are summarized in Table 1.

\section{Differences in immature DCs percentages between JIA patients and control groups}

We found that children with JIA have significantly lower percentages of circulating myeloid and plasmacytoid DCs $(p=0.0003$ and $p=0.0002$ respectively). Decreasing percentages of both DCs subpopulations lead to significantly ( $p=0.000003$ ) lower total percentage of DCs. When comparing inflammatory synovial fluid to post-traumatic synovial fluid, we found significantly higher percentages of myeloid and plasmacytoid DCs ( $\mathrm{p}=0.000000003$ and $p=0.0000009$ respectively) as well as total percentage of DCs $(\mathrm{p}=0.000000005)$ in children with JIA. Differences were also significant for each examined subtype of juvenile idiopathic arthritis. We did not find significant differences in myeloid/plasmacytoid ratio, either in blood or synovial fluid. Percentages of analyzed cells populations are summarized in Table 1.

\section{Differences in DCs expressing CD83 and CD1a in peripheral blood and synovial fluid of children with JIA}

We found higher percentages of CD83 ${ }^{+} / \mathrm{HLA}-\mathrm{DR}^{+}$ $(\mathrm{p}=0.0002)$ and $\mathrm{CD} 1 \mathrm{a}^{+} / \mathrm{HLA}^{-\mathrm{DR}^{+}}(\mathrm{p}=0.003)$ cells 

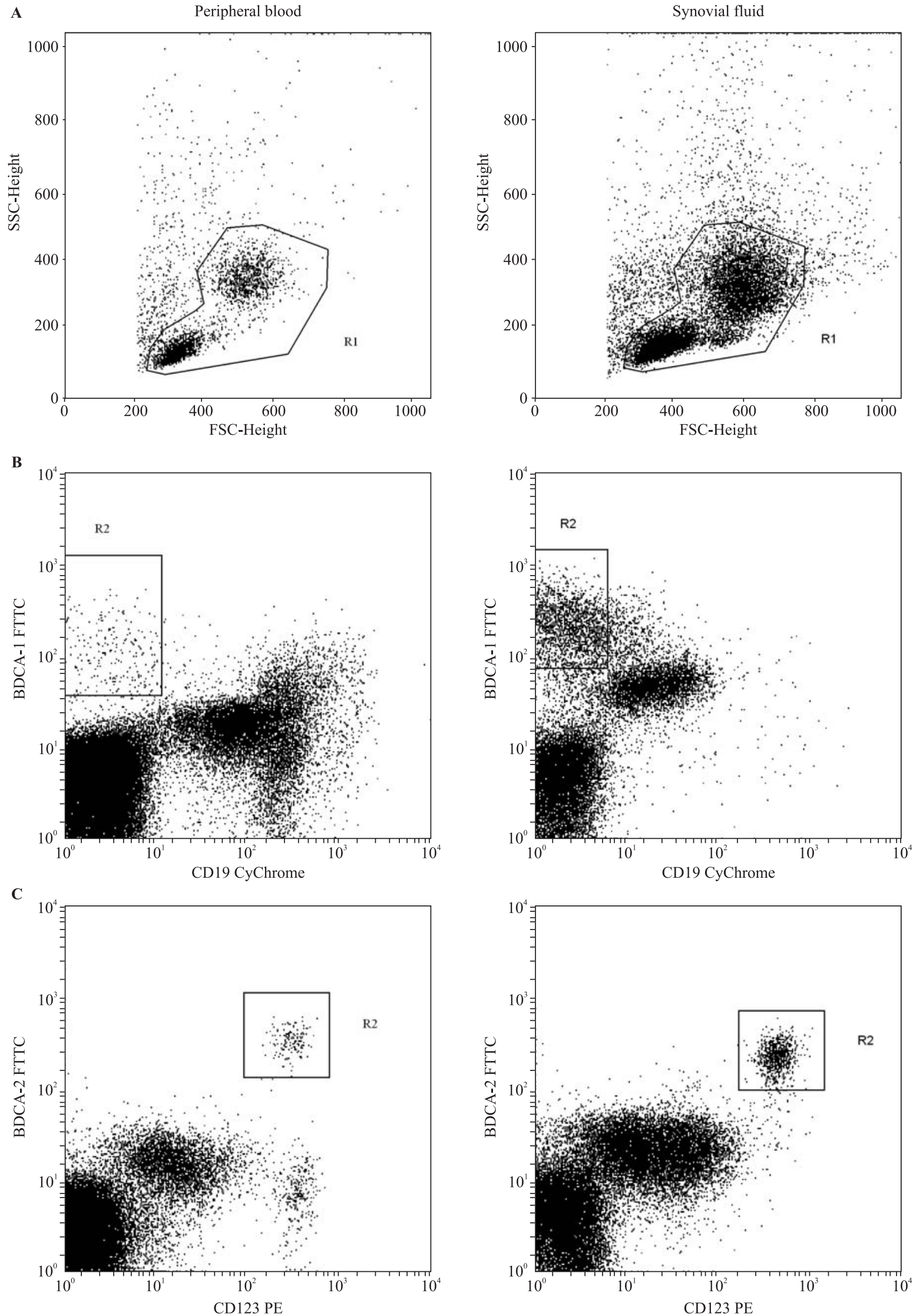

Figure 1. Cytometric analysis of $\mathrm{CD} 1 \mathrm{c}^{+} / \mathrm{CD} 19^{-}$and $\mathrm{CD} 303^{+} / \mathrm{CD} 123^{+}$dendritic cells in peripheral blood and synovial fluid of representative patient with JIA. A. Gating of PBMCs - R1; B. Gating of myeloid DCs - R2; C. Gating of plasmacytoid DCs - R2 
A

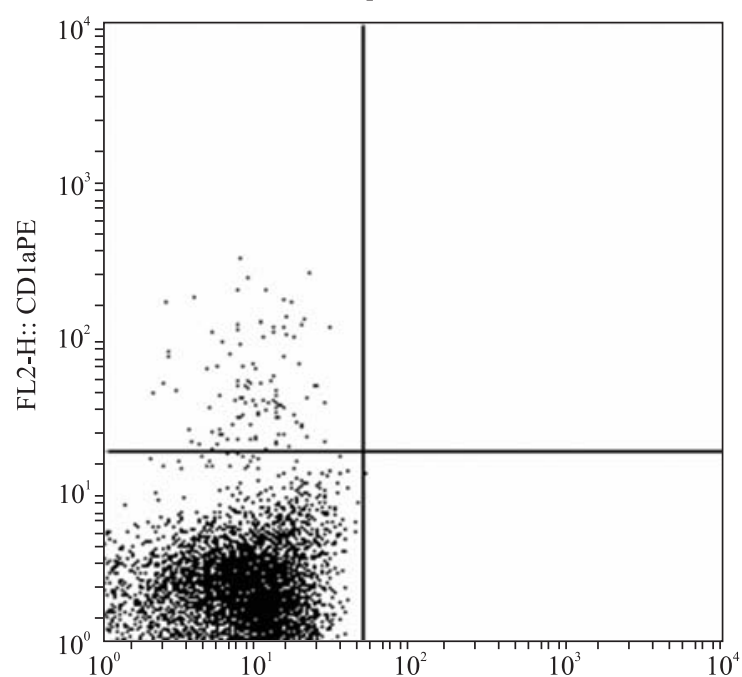

B

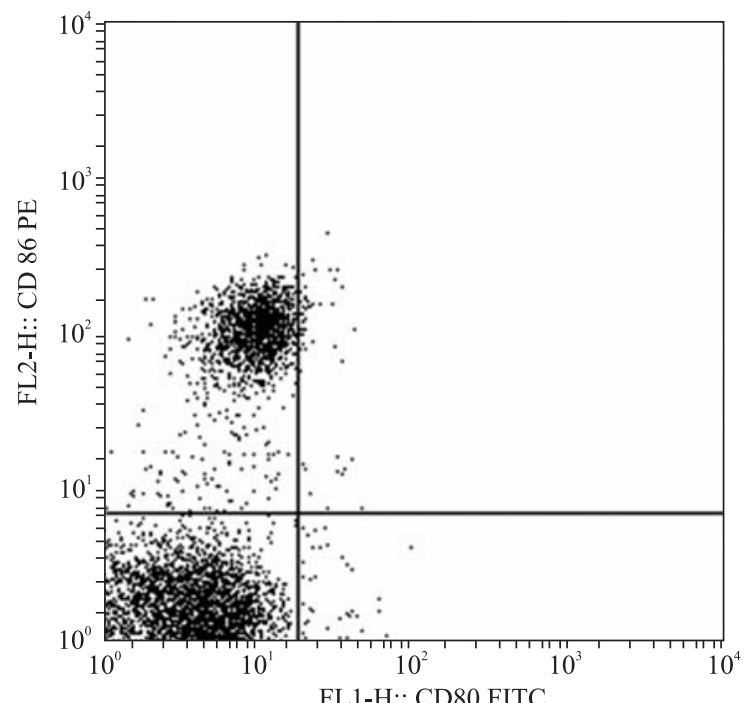

C

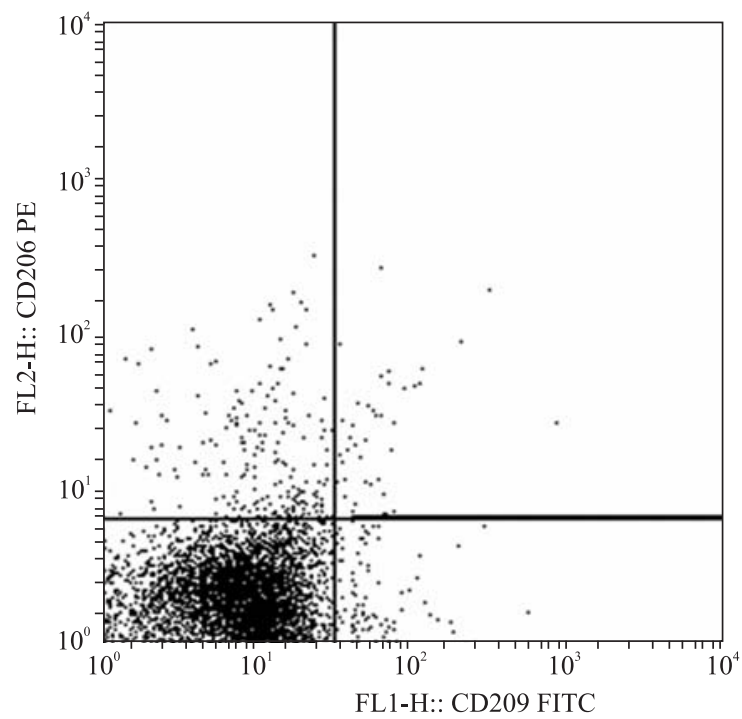

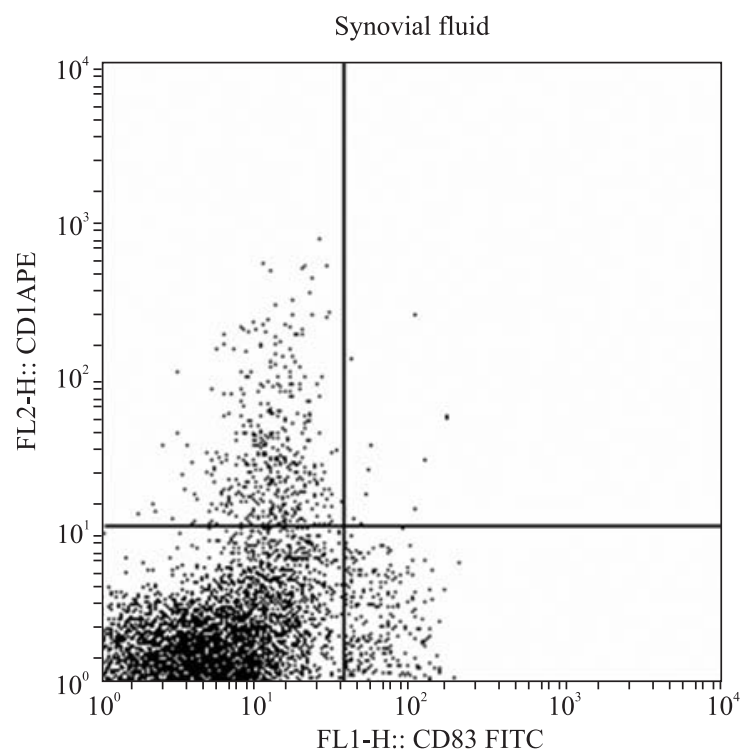

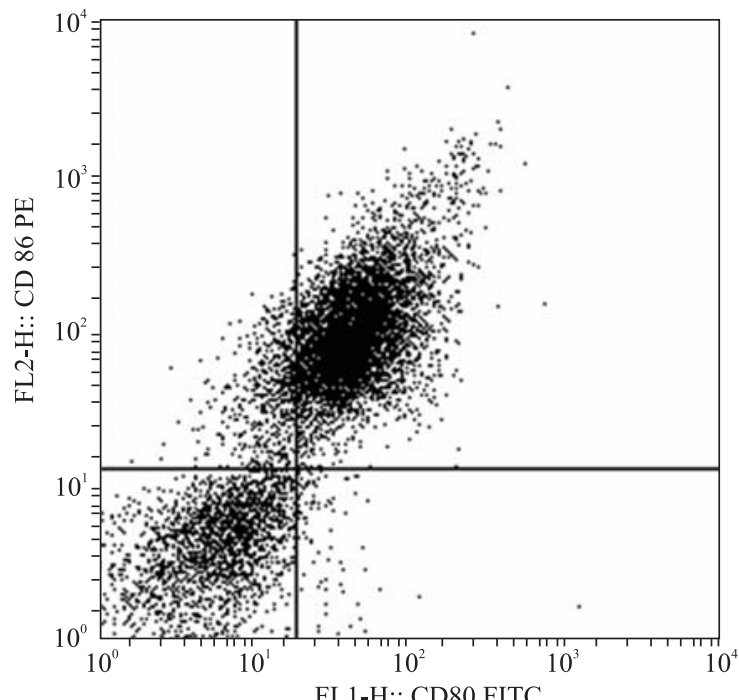

FL1-H:: CD80 FITC

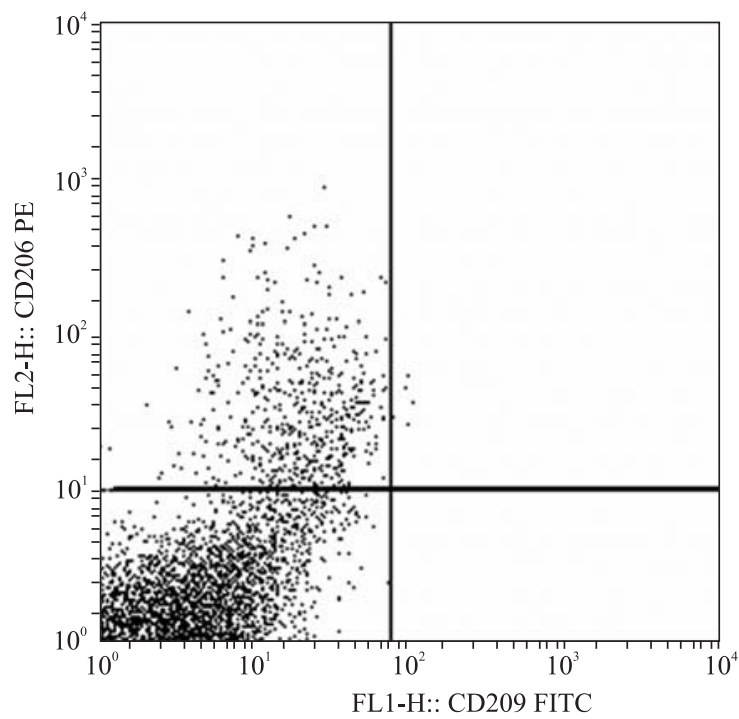

Figure 2. Dot-plots representing cytometric analysis of representative patient with JIA. A. Gating of CD83 and CD1a positive cells; B. Gating of CD80 CD86 positive cells; C. Gating of CD209 and CD206 positive cells 


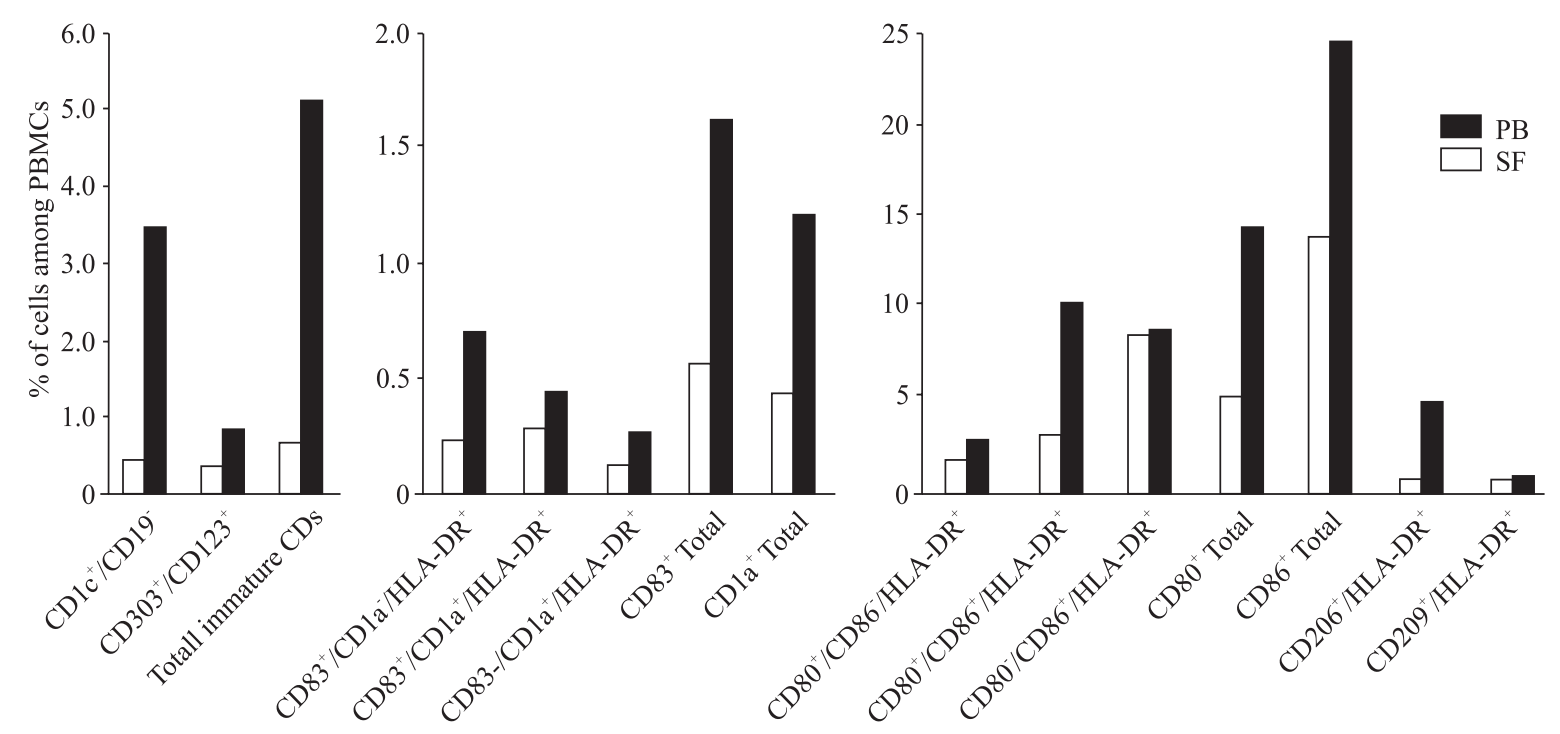

Figure 3. Percentages (shown as medians) of cell populations expressing different DCs markers in peripheral blood and synovial fluid of children with JIA. All differences were statistically significant, except comparison of CD80-/ $/ \mathrm{CD}^{2} 6^{+} / \mathrm{HLA}^{-\mathrm{DR}^{+}}$cells

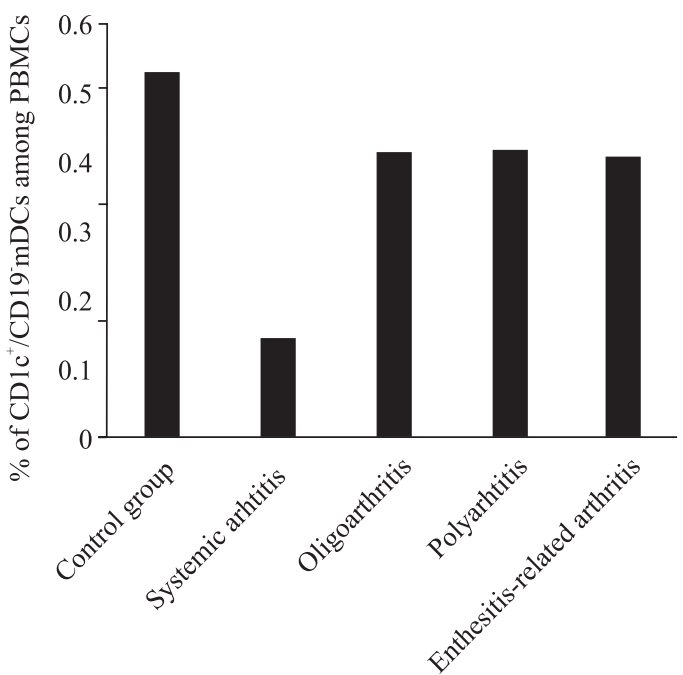

Figure 4. Percentage of circulating myeloid dendritic cells was lowest in children with systematic JIA. ANOVA statistical analysis of different subtypes of JIA revealed significant difference $(\mathrm{H}=8.36 ; \mathrm{p}=0.04)$. This difference was confirmed by paired analysis and percentage of circulating mDCs was lower than in control group $(p=0.00004)$, oligoarthritis $(p=0.004)$, polyarthritis $(p=0.01)$, enthesitis-related arthritis $(p=0.01)$

in SF than in PB (Figure 3). When we analyzed coexpression of CD83 and CD1a, we concluded that all populations: $\mathrm{CD} 83^{+} / \mathrm{CD} 1 \mathrm{a}^{-} / \mathrm{HLA}^{-} \mathrm{DR}^{+}, \mathrm{CD}^{+} 3^{+} /$ $/ \mathrm{CD}^{+} \mathrm{a}^{+} / \mathrm{HLA}-\mathrm{DR}^{+}, \mathrm{CD} 83^{-} / \mathrm{CD} \mathrm{a}^{+} / \mathrm{HLA}^{-\mathrm{DR}^{+} \text {, were }}$ significantly accumulated in synovial fluid $\mathrm{p}=0.0001$, $p=0.003, p=0.002$ respectively (Figure 3 ). We did not find any statistically significant differences in CD83 and CD1a expressing cells of children with different disease onsets. Comparison between JIA pa- tients and healthy children revealed that percentages of $\mathrm{CD}^{2} 3^{+} / \mathrm{HLA}-\mathrm{DR}^{+}$and CD1a/HLA-DR ${ }^{+}$cells were higher in the $\mathrm{PB}$ of children with juvenile arthritis, $\mathrm{p}=0.03$ and $\mathrm{p}=0.02$ respectively (Table 1 ). We also concluded that CD83/CD1a double positive and $\mathrm{CD}^{2} 3^{-} / \mathrm{CD} \mathrm{a}^{+} / \mathrm{HLA}-\mathrm{DR}^{+}$populations were significantly $(\mathrm{p}=0.02$ and $\mathrm{p}=0.04$ respectively) accumulated in the blood of JIA patients, but not $\mathrm{CD} 3^{+} / \mathrm{CD}^{-} \mathrm{a}^{-} / \mathrm{HLA}-\mathrm{DR}^{+}$cells. In inflammatory SF we found a significantly $(p=0.03)$ higher total percentage of $\mathrm{CD}^{8} 3^{+} / \mathrm{HLA}^{-} \mathrm{DR}^{+}$, but not $\mathrm{CD} 1 \mathrm{a}^{+} / \mathrm{HLA}-$ $-\mathrm{DR}^{+}$cells when compared to post-traumatic SF. Unlike with blood, in JIA SF we found a significantly $(\mathrm{p}=0.04)$ higher percentage of $\mathrm{C}^{2} 3^{+} / \mathrm{CD} 1 \mathrm{a}^{-} / \mathrm{HLA}^{-}$ $-\mathrm{DR}^{+}$cells, but not $\mathrm{CD}^{2} 3^{+} / \mathrm{CD} 1 \mathrm{a}^{+} / \mathrm{HLA}-\mathrm{DR}^{+}$cells. $\mathrm{CD}^{2} 3^{-} / \mathrm{CD} \mathrm{a}^{+} / \mathrm{HLA}-\mathrm{DR}^{+}$cells were also significantly higher in the SF of children with JIA compared to controls. Percentages of cells bearing particular immunophenotypes are shown in Table 1.

\section{$C D 80$ and CD86 expressing cells in the $P B$ and SF of JIA patients}

Our results showed that percentages of $\mathrm{CD} 80^{+} / \mathrm{HLA}-$ $-\mathrm{DR}^{+}$and $\mathrm{CD}^{+} 6^{+} / \mathrm{HLA}-\mathrm{DR}^{+}$were significantly $(\mathrm{p}=$ $=0.01$ and $\mathrm{p}=0.005$ respectively) higher in the $\mathrm{SF}$ than in the PB of JIA children (Figure 3). Analysis of co-expression of CD80 and CD86 revealed that numbers of double positive CD80 and CD86, as well as CD $80-/ \mathrm{CD}^{2} 6^{+} / \mathrm{HLA}-\mathrm{DR}^{+}$cells, were significantly $(\mathrm{p}=$ $=0.01$ and $\mathrm{p}=0.04$ ) higher in synovial fluid (Figure 3). We did not confirm a difference in the $\mathrm{CD} 80^{+} / \mathrm{CD} 86^{-} /$ $/$ HLA-DR $^{+}$population. We also did not observe any significant differences between JIA onset subtypes. 
Table 1. Percentages of the cells of particular immunophenotypes in mononuclear cells gate. Results are shown as median followed by IQR. Significant differences between groups are described in the 'Results' section of the text

\begin{tabular}{|c|c|c|c|c|c|}
\hline \multirow[t]{3}{*}{ Immunophenotype } & \multicolumn{5}{|c|}{ Percentage of cells among PBMCs } \\
\hline & \multicolumn{5}{|c|}{ Peripheral blood } \\
\hline & JIA n $=220$ & $\begin{array}{c}\text { Systemic } \\
\text { arthritis } n=11\end{array}$ & $\begin{array}{c}\text { Polyarthritis } \\
\text { n }=55\end{array}$ & $\begin{array}{l}\text { Oligoarthritis } \\
\mathbf{n}=121\end{array}$ & $\begin{array}{c}\text { Enthesitis- } \\
\text {-related arthritis } \\
\quad \mathbf{n}=\mathbf{3 3}\end{array}$ \\
\hline $\mathrm{CD} 1 \mathrm{c}^{+} / \mathrm{CD} 19^{-} \mathrm{mDCs}$ & $0.43(0.31)$ & $0.16(0.26)$ & $0.43(0.31)$ & $0.43(0.30)$ & $0.43(0.25)$ \\
\hline $\mathrm{CD} 303^{+} / \mathrm{CD} 123^{+} \mathrm{pDCs}$ & $0.35(0.37)$ & $0.14(0.40)$ & $0.34(0.42)$ & $0.38(0.34)$ & $0.30(0.40)$ \\
\hline Total immature DCs & $0.79(0.61)$ & $0.36(0.86)$ & $0.79(0.77)$ & $0.83(0.55)$ & $0.82(0.66)$ \\
\hline mDCs/pDCs Ratio & $1.20(1.30)$ & $1.17(2.70)$ & $1.28(1.58)$ & $1.18(1.22)$ & $1.32(1.30)$ \\
\hline $\mathrm{CD}^{2} 3^{+} / \mathrm{CD} 1 \mathrm{a}^{-} / \mathrm{HLA}^{-\mathrm{DR}^{+}}$ & $0.23(0.23)$ & $0.22(0.15)$ & $0.24(0.27)$ & $0.21(0.25)$ & $0.23(0.20)$ \\
\hline $\mathrm{CD}^{2} 3^{+} / \mathrm{CD} 1 \mathrm{a}^{+} / \mathrm{HLA}-\mathrm{DR}^{+}$ & $0.27(0.41)$ & $0.06(0.26)$ & $0.35(0.49)$ & $0.32(0.42)$ & $0.14(0.27)$ \\
\hline $\mathrm{CD}^{2} 3^{-} / \mathrm{CD} 1 \mathrm{a}^{+} / \mathrm{HLA}^{-\mathrm{DR}^{+}}$ & $0.11(0.20)$ & $0.05(0.15)$ & $0.17(0.14)$ & $0.11(0.20)$ & $0.07(0.20)$ \\
\hline${\mathrm{CD} 83^{+} / \mathrm{HLA}-\mathrm{DR}^{+} \text {Total }}$ & $0.56(0.65)$ & $0.28(0.39)$ & $0.64(0.69)$ & $0.62(0.65)$ & $0.35(0.27)$ \\
\hline $\mathrm{CD}_{1} \mathrm{a}^{+} / \mathrm{HLA}-\mathrm{DR}^{+}$Total & $0.43(0.63)$ & $0.11(0.41)$ & $0.52(0.55)$ & $0.40(0.67)$ & $0.34(0.39)$ \\
\hline $\mathrm{CD} 80^{+} / \mathrm{CD} 86^{-} / \mathrm{HLA}^{-\mathrm{DR}^{+}}$ & $1.83(2.08)$ & $1.25(1.50)$ & $1.63(2.09)$ & $1.95(2.13)$ & $2.22(1.75)$ \\
\hline $\mathrm{CD}^{2} 0^{+} / \mathrm{CD} 86^{+} / \mathrm{HLA}^{-\mathrm{DR}^{+}}$ & $3.07(6.16)$ & $5.09(7.74)$ & $2.59(4.86)$ & $2.63(5.21)$ & $5.89(9.13)$ \\
\hline $\mathrm{CD} 80^{-} / \mathrm{CD} 86^{+} / \mathrm{HLA}^{-\mathrm{DR}^{+}}$ & $8.59(8.89)$ & $10.07(12.30)$ & $8.96(7.90)$ & $8.14(8.71)$ & $9.14(8.05)$ \\
\hline $\mathrm{CD} 80^{+} / \mathrm{HLA}-\mathrm{DR}^{+}$Total & $5.26(7.45)$ & $6.57(11.67)$ & $4.22(6.16)$ & $5.28(6.75)$ & $8.78(11.12)$ \\
\hline $\mathrm{CD} 86^{+} / \mathrm{HLA}-\mathrm{DR}^{+}$Total & $13.90(9.75)$ & $15.38(13.74)$ & $13.57(11.96)$ & $13.86(10.28)$ & $15.97(7.04)$ \\
\hline $\mathrm{CD}^{206^{+}} / \mathrm{HLA}^{-\mathrm{DR}^{+}}$Total & $0.64(0.51)$ & $0.44(0.76)$ & $0.43(0.41)$ & $66(0.56)$ & $0.57(0.10)$ \\
\hline $\mathrm{CD}^{209^{+}} / \mathrm{HLA}^{-\mathrm{DR}^{+}}$Total & $0.68(0.39)$ & $0.47(0.51)$ & $0.84(0.92)$ & $0.68(0.39)$ & $0.69(0.51)$ \\
\hline $\begin{array}{l}\text { CD206 }{ }^{+} \text {among } \\
\text { CD209 } 9^{+}-/ \text {HLA-DR }{ }^{+}\end{array}$ & $47.00(29.00)$ & $43.00(58.00)$ & $31.00(26.00)$ & $42.00(29.00)$ & $58.00(18.00)$ \\
\hline
\end{tabular}

Comparison between the PB of children with JIA and the control group showed significant difference only in percentage of $\mathrm{CD} 80^{-} / \mathrm{CD}^{+} 6^{+} / \mathrm{HLA}-\mathrm{DR}^{+}$cells, which were in lower numbers in the blood samples of JIA patients. When we compared inflammatory SF to posttraumatic SF, we concluded that percentages of $\mathrm{CD}^{2} 0^{+} /$ $/ \mathrm{HLA}_{-} \mathrm{DR}^{+}$cells and CD86 ${ }^{+} / \mathrm{HLA}-\mathrm{DR}^{+}$were significantly $(p=0.00002$ and $p=0.009)$ higher in inflamed joints. These differences were made by $\mathrm{CD} 80^{+} / \mathrm{CD} 86^{-} /$ $/ \mathrm{HLA}_{-} \mathrm{DR}^{+}(\mathrm{p}=0.00003)$ and $\mathrm{CD} 80^{+} / \mathrm{CD}^{2} 6^{+} / \mathrm{HLA}-$ $-\mathrm{DR}^{+}(\mathrm{p}=0.0001)$, and there was no significant difference in $\mathrm{CD} 80^{-} / \mathrm{CD}^{+} 6^{+} / \mathrm{HLA}-\mathrm{DR}^{+}$population. Percentages of each cells population are set out in Table 1.

\section{Analysis of CD206 positive cells in blood and synovial fluid}

We found a significantly $(\mathrm{p}=0.001)$ higher percentage of $\mathrm{CD}^{206} / \mathrm{HLA}^{+} \mathrm{DR}^{+}$cells in SF than in $\mathrm{PB}$ of children with JIA (Figure 3); also, expression of CD206 shown as MFI (Mean Fluorescence Intensity) was higher $(p=0.005)$ on mononuclear cells from $\mathrm{SF}$ than in PB. There were no differences in the percentage of positive cells or expression of CD206 between different types of JIA onset. Comparison bet- ween JIA patients and controls revealed a higher $(\mathrm{p}=0.04)$ percentage of $\mathrm{CD} 206^{+} / \mathrm{HLA}-\mathrm{DR}^{+}$cells in the blood of children with arthritis. We did not observe any further differences in CD206 ${ }^{+}$cells. Results are summarized in Table 1.

\section{Analysis of CD209 positive cells in blood and synovial fluid}

We found a significantly $(\mathrm{p}=0.04)$ higher percentage of CD209 ${ }^{+} / \mathrm{HLA}-\mathrm{DR}^{+}$cells in SF than in PB (Figure 3), also expression of CD209 on SF mononuclear leukocytes was higher $(p=0.005)$. Patients with different types of JIA onset did not differ in percentage of CD209+ cells and expression of this molecule. We noticed higher percentages of CD209+/HLA$-\mathrm{DR}^{+}$cells in both blood $(\mathrm{p}=0.03)$ and synovial fluid $(\mathrm{p}=0.02)$ compared to controls. MFI of CD209 did not differ significantly between JIA children and control samples. We also found that the percentage of CD209+ expressing CD206 was significantly $(\mathrm{p}=0.005)$ higher in JIA SF than in JIA PB. We did not confirm any differences in $\mathrm{CD} 209^{+} / \mathrm{CD} 206^{+}$cells between patients suffering different subtypes of arthritis and between patients and reference groups. 
Table 1. Continued

\begin{tabular}{|c|c|c|c|c|c|c|}
\hline \multicolumn{7}{|c|}{ Percentage of cells among PBMCs } \\
\hline & & & Synovial fluid & & & \\
\hline $\begin{array}{l}\text { Control } \\
\mathbf{n}=\mathbf{5 0}\end{array}$ & JIA n $=52$ & $\begin{array}{c}\text { Systemic } \\
\text { arthritis } \\
\mathbf{n}=\mathbf{0}\end{array}$ & $\begin{array}{c}\text { Polyarthritis } \\
n=5\end{array}$ & $\begin{array}{c}\text { Oligoarthritis } \\
n=40\end{array}$ & $\begin{array}{c}\text { Enthesitis- } \\
\text {-related arthritis } \\
\quad \mathbf{n}=7\end{array}$ & Control $n=20$ \\
\hline $0.55(0.20)$ & $3.47(3.55)$ & - & $2.77(2.66)$ & $3.30(3.56)$ & $4.78(4.53)$ & $0.17(0.80)$ \\
\hline $0.51(0.28)$ & $0.84(1.56)$ & - & $1.27(1.34)$ & $0.88(1.54)$ & $0.32(0.34)$ & $0.07(0.24)$ \\
\hline $1.03(0.46)$ & $5.13(4.08)$ & - & $4.59(4.13)$ & $5.18(3.61)$ & $5.43(4.89)$ & $0.20(1.05)$ \\
\hline $1.06(1.04)$ & $4.58(6.95)$ & - & $6.52(7.83)$ & $3.71(6.30)$ & $9.76(13.35)$ & $1.49(13.45)$ \\
\hline $0.18(0.21)$ & $0.71(0.99)$ & - & $1.18(2.16)$ & $0.56(1.09)$ & $0.90(0.86)$ & $0.40(0.34)$ \\
\hline $0.07(0.09)$ & $0.45(1.53)$ & - & $0.40(1.56)$ & $0.46(1.48)$ & $1.80(1.88)$ & $1.44(2.03)$ \\
\hline $0.06(0.13)$ & $0.26(0.63)$ & - & $0.26(0.19)$ & $0.29(0.74)$ & $0.21(0.22)$ & $0.09(0.07)$ \\
\hline $0.26(0.37)$ & $1.62(2.46)$ & - & $1.58(2.60)$ & $1.66(2.61)$ & $2.70(2.74)$ & $0.74(0.57)$ \\
\hline $0.14(0.29)$ & $1.21(2.18)$ & - & $0.66(0.95)$ & $1.16(2.75)$ & $2.00(1.67)$ & $0.56(1.70)$ \\
\hline $1.25(2.75)$ & $2.90(4.09)$ & - & $3.44(4.12)$ & $2.54(3.07)$ & $5.20(7.32)$ & $0.06(0.04)$ \\
\hline $2.91(5.49)$ & $10.38(15.66)$ & - & $22.67(28.60)$ & $10.76(13.94)$ & $3.52(20.67)$ & $0.53(0.25)$ \\
\hline $13.19(12.40)$ & 8.80 (18.72) & - & $5.75(9.25)$ & $10.68(18.25)$ & $8.80(24.35)$ & $12.37(13.28)$ \\
\hline $4.52(7.74)$ & $14.51(18.65)$ & - & $26.11(31.20)$ & $14.33(17.93)$ & $10.88(25.83)$ & $0.57(0.22)$ \\
\hline $17.81(9.11)$ & $24.79(21.11)$ & - & $28.42(39.44)$ & $24.60(21.37)$ & $28.33(24.63)$ & $12.87(13.48)$ \\
\hline $0.26(0.24)$ & $4.92(6.26)$ & - & $0.85(1.28)$ & $4.42(6.75)$ & $4.91(0.31)$ & $3.88(4.40)$ \\
\hline $0.25(0.40)$ & $1.14(2.09)$ & - & $0.78(1.11)$ & $1.40(2.22)$ & $0.63(0.39)$ & $0.51(0.54)$ \\
\hline $29.00(20.00)$ & $76.00(48.00)$ & - & $79.00(30.54)$ & $75.00(50.00)$ & $74.00(8.00)$ & $61.00(29.00)$ \\
\hline
\end{tabular}

\section{HLA-DR positive cells in blood and synovial fluid}

The total percentage of HLA-DR positive cells did not differ between PB and SF of children with JIA. On the other hand, expression of HLA-DR was significantly $(\mathrm{p}=0.003)$ higher in synovial fluid. We did not found any differences in the percentage of HLA-DR positive cells between JIA subtypes or JIA children compared to control groups. Percentages of each population are shown in Table 1.

\section{Discussion}

Dendritic cells are thought to play a pivotal role in driving the immunopathogenic response essential for chronic inflammatory arthritis. Multiple studies have showed accumulation of DCs, at different maturation stages and of different lineage, in synovial fluid and synovial tissue of patients with rheumatoid arthritis [8-15]. Smolewska et al. described the accumulation of DCs in the synovial fluid of children with juvenile idiopathic arthritis [16-17]. Since the pathogenesis of JIA is still unknown, the evaluation of dendritic cells distribution in peripheral blood and synovial compartment may be important in understanding the immunopathogenesis of chronic synovial inflammation and cartilage destruction. Our study shows for the first time the results of complex evaluation of dendritic cells of different lineages and maturation stages in a large cohort of patients with JIA.

Our results showed a significant decrease in circulating $\mathrm{CD} 1 \mathrm{c}^{+} / \mathrm{CD} 19^{-}$myeloid and $\mathrm{CD} 303^{+} / \mathrm{CD} 123^{+}$ plasmacytoid DCs in children with JIA, compared to healthy children. Decreased peripheral blood dendritic cells percentages most probably reflect DCs migration and accumulation to the inflamed joints. This is consistent with our results showing significantly higher percentages of mDCs as well as pDCs in paired synovial fluid collected during therapeutic joint puncture. To confirm that greater levels of DCs are characteristic of inflammatory SF, we checked the presence of dendritic cells in post-traumatic synovial fluid. We found that SF from inflamed joints contains significantly higher percentages of mDCS and pDCs than post-traumatic SF. Jongbloed et al. showed similar results in patients with RA, when they checked absolute count of $\mathrm{CD} 1 \mathrm{c}^{+}$and $\mathrm{CD} 303^{+}$DCs [14]. Richez et al. found similar results for $\mathrm{CD} 11 \mathrm{c}^{+} / \mathrm{HLA}-\mathrm{DR}^{+}$ $\mathrm{mDCs}$ and $\mathrm{CD} 123^{+} / \mathrm{HLA}-\mathrm{DR}^{+} \mathrm{pDCs}$ enumerated in blood and synovial fluid of patients with rheumatoid 
arthritis [18]. Cavanagh et al. also described a higher percentage of myeloid and plasmacytoid DCs in RA SF, but only PB mDCs, not pDCs, were decreased when compared to the blood of healthy donors [15]. Kavousanaki et al. found decreased percentages of $\mathrm{CD} 45^{+} / \mathrm{CD} 1 \mathrm{c}^{+} / \mathrm{CD} 11 \mathrm{c}^{+} / \mathrm{CD} 303^{-}$myeloid DCs and $\mathrm{CD} 03^{+}$plasmacytoid DCs in patients with active rheumatoid arthritis, but not during remission [12]. They also described high number of $\mathrm{mDCs} \approx 15 \%$ in inflammatory SF. On the other hand, surprisingly, they were not able to detect any CD303 ${ }^{+}$in SF. Deficiency in circulating $\mathrm{mDCs}$ and $\mathrm{pDCs}$, as well as accumulation of DCs in the synovial compartment in children with JIA, have been described by Smolewska et al. and their results accord with ours [16]. Jongbloed et al. and Smolewska et al. described significantly increased mDCs to $\mathrm{pDCs}$ ratios in RA and JIA respectively $[14,16]$. These findings are consistent with our results.

Dendritic cells are thought to be very potent inducers of specific immune response, but they also play an important role in the maintenance of immune tolerance. Immunostimulatory or tolerogenic features of DCs depend on lineage and maturation stage. We showed accumulation of both populations $\mathrm{CD} 1 \mathrm{c}^{+}$/ $/ \mathrm{CD}^{-}{ }^{-}$and $\mathrm{CD}^{-} 3^{+} / \mathrm{CD} 123^{+}$in inflamed joint environment, and these findings prompt us to raise the question whether DCs in SF are proinflammatory cells, or represent a cell population which loses regulatory potential. Dendritic cells expressing $\mathrm{CD} 1 \mathrm{c}^{+}$or $\mathrm{CD} 03^{+}$are either considered as immature or maturating DCs [4]. Lim et al. showed that semi-mature CD11c+ DCs are immunogenic and, when injected at a high dose, they accelerated collagen-induced arthritis in mice. Only low doses of these cells showed anti-arthritic activity [19]. Cavanagh et al. confirmed that mDCs and pDCs isolated from RA SF efficiently stimulated proliferation and IFN- $\gamma$ and IL-10 production by resting normal allogeneic $\mathrm{T}$ lymphocytes [15]. Contradicting the results described above, Kavousanaki et al. found that plasmacytoid DCs could be educated within the rheumatoid microenvironment to acquire tolerogenic phenotype [12]. They showed that matured pDCs from RA patients with low disease activity, but not from healthy donors, expressed high levels of indoleamine 2,3-dioxygenase and promoted differentiation of IL-10 positive T regulatory lymphocytes. Using a mouse model of arthritis, Jongbloed et al. showed that selective in vivo depletion of $\mathrm{pDCs}$ enhanced $\mathrm{T}$ and $\mathrm{B}$ cells immune response against collagen and severity of articular inflammation [20]. Furthermore, immature and mature myeloid DCs can expand Treg numbers, which are able to block the maturation of further dendritic cells
[21-23]. Sidhu et al. showed that vaccination with immature DCs pulsed with type II collagen could significantly delay the onset of mouse spontaneous polychondritis [24]. These results open the gates for using DCs in the therapy of human arthritis.

Systemic juvenile idiopathic arthritis (sJIA) is a rare, systemic inflammatory disease characterized by arthritis and systemic features such as spiking fever, skin rash, hepatosplenomegaly or serositis. Nowadays, it is clear that abnormalities in the innate immunity play a crucial role in the development of sJIA. Moreover, this subtype of arthritis is strongly associated with macrophage activation syndrome.

In this present paper, we showed that patients with sJIA represent the lowest percentages of circulating $\mathrm{CD} 1 \mathrm{c}^{+}$myeloid dendritic cells, and this difference was confirmed in Kruskal-Wallis test and paired analysis. Unfortunately, we were unable to collect SF samples from any patients with sJIA. Our results could support previous work which has revealed that it is mainly cells of myeloid lineage that participate in the pathogenesis of sJIA [25]. Contradicting our results, Macaubas et al. showed a decrease not only in circulating $\mathrm{mDCs}$, but also in $\mathrm{pDCs}$, in patients with active sJIA [26].

Human CD83 is a $45-\mathrm{kDa}$ glycoprotein and a member of the Ig superfamily expressed on mature dendritic cells [27]. CD1a belongs to the highly conserved and closely related group of CD1 proteins, which mediate the presentation of primarily lipid and glycolipid antigens of self or microbial origin to T cells [28].

In this study, we checked co-expression of CD83 and CD1a in peripheral blood and synovial fluid of children with JIA. We found significantly higher percentages of $\mathrm{CD}^{2} 3^{+} / \mathrm{CD} 1 \mathrm{a}^{-} / \mathrm{HLA}-\mathrm{DR}^{+}, \mathrm{CD}^{2} 3^{+} /$ $/ \mathrm{CD} \mathrm{a}^{+} / \mathrm{HLA}-\mathrm{DR}^{+}, \mathrm{CD}^{2} 3^{-} / \mathrm{CD} 1 \mathrm{a}^{+} / \mathrm{HLA}_{-}-\mathrm{DR}^{+}$in synovial fluid than in peripheral blood. Previous research has confirmed the presence of cells expressing CD1a or CD83 in the synovial tissue of patients with arthritis $[9,10,29,30]$. Smolewska et al. confirmed expression of $\mathrm{C} 83$ on CD1c positive dendritic cells in the synovial fluid of JIA patients [17]. The CD83 molecule could be important not only when expressed on the cell surface, but also in soluble form. Hock et al. confirmed a higher concentration of sCD83 in RA SF than in the synovial fluid of patients with osteoarthritis [31]. The role of $\mathrm{CD}_{1} \mathrm{a}^{+}$dendritic cells in cartilage destruction is not restricted to stimulation of immune response; they could actively destroy joint structures. Rivollier et al. showed that in the arthritis microenvironment, CD1a ${ }^{+} / \mathrm{HLA}-\mathrm{DR}^{+} /$ /CD83low/CD80low/CD86low dendritic cells are capable of turning into active osteoclasts [32]. Lakey et 
al. proved that mature monocytes derived dendritic cells destroy cartilage collagen through an indirect mechanism mediated by TNF- $\alpha$ [33]. We also concluded that percentages of dendritic cells expressing CD1a: $\mathrm{CD}_{3} 3^{+} / \mathrm{CD} 1 \mathrm{a}^{+} / \mathrm{HLA}-\mathrm{DR}{ }^{+}$and $\mathrm{CD} 83^{-} /$ $/ \mathrm{CD} \mathrm{a}^{+} / \mathrm{HLA}-\mathrm{DR}^{+}$were higher in the $\mathrm{PB}$ of children with JIA. On the other hand, in synovial fluid we found higher percentages of $\mathrm{CD}^{2} 3^{+} / \mathrm{CD} 1 \mathrm{a}^{-} / \mathrm{HLA}-$ $-\mathrm{DR}^{+}$and $\mathrm{CD}^{-} 3^{-} / \mathrm{CD} 1 \mathrm{a}^{+} / \mathrm{HLA}-\mathrm{DR}^{+}$than in posttraumatic SF. This finding suggests that inflammatory synovial fluid can induce maturation of DCs and upregulation of CD83 and loss of CD1a, so in inflammatory SF we see relatively small amounts of semimature CD83/CD1a double positive cells. Our group confirmed that inflammatory synovial fluid is an efficient inducer of monocytes derived dendritic cells generation and maturation [34]. In agreement with our results, Saito et al. confirmed the paucity of $\mathrm{CD} \mathrm{a}^{+}$expressing cells in the synovial tissue of patients with osteoarthritis [35]. Our data, supported by reviewed articles, strengthens the thesis that the synovial microenvironment during autoimmune arthritis, such as RA and JIA, attracts dendritic cells, which become mature in inflamed joints. On the other hand, it has been proved that C-reactive protein as well as immune complexes inhibit the differentiation, maturation and function of monocytes derived dendritic cells $[36,37]$.

CD80 (B7-1) and CD86 (B7-2) are both type 1 transmembrane proteins, which mediate costimulation of T-cell activation and differentiation, and may therefore affect the course of different human diseases $[38,39]$. Our study showed higher total percentages of cells expressing both costimulatory molecules in SF than in PB of children with JIA. Also, when we compared blood and synovial fluid of patients to samples from the control group, we found a decrease of CD $80^{-} / \mathrm{CD}^{-} 6^{+} / \mathrm{HLA}-\mathrm{DR}$ in JIA PB and $\mathrm{CD} 80^{+} /$ $/ \mathrm{CD}^{2} 6^{+} / \mathrm{HLA}^{-\mathrm{DR}^{+}}$as well as $\mathrm{CD} 80^{+} / \mathrm{CD} 86^{-} / \mathrm{HLA}-$ $-\mathrm{DR}^{+}$in JIA SF.

These results indicate that inflammatory SF induces maturation of DCs, because CD86 is constitutively expressed on APCs, unlike CD80, the expression of which is induced. Using the mouse model of Streptococcus-induced arthritis, Puliti et al. showed that lack of CD80 resulted in a lower incidence and severity of articular lesions, while lack of CD86 led to worsening of arthritis [38].

CD209 (DC-SIGN) is a C-type lectin expressed on phagocytic cells such as DCs and macrophages which is involved in the infectious pathogen recognition and stimulation of innate immune response [40-42]. CD206 (mannose receptor, also known as the macrophage mannose receptor) has been shown to bind and internalize carbohydrate and collagen ligands and to have a role in myoblast motility and muscle growth [43]. We confirmed the accumulation of CD206 or CD209 expressing cells in the synovial fluid of children with JIA, and also that double positive cells were found in higher numbers in SF. The percentage of CD206 positive cells was higher in the blood of children with JIA, but was no difference in SF when compared to controls. CD209 were accumulated in PB and SF when compared to the blood of healthy children or post-traumatic synovial fluid. Accumulation of CD209+ could confirm mature state of DCs in inflammatory synovial fluid, but Ochoa et al. showed that DC-SIGN is expressed on CD206+ macrophages with DCs-like morphology [44]. Additionally, Dieguez-Gonzales et al. showed in single nucleotide polymorphism a lack of association of CD209 encoding genes with rheumatoid arthritis [41].

In summary, our investigation is the first study describing dendritic cells population in juvenile idiopathic arthritis in which a large cohort of 220 patients with active JIA was included. Our research compared inflammatory SF to post-traumatic SF (collected a short time after injury), unlike other studies of synovial fluid from patients with osteoarthritis. Because of this difference, we were able to compare SF not between two inflammatory diseases, but between autoimmune inflammation and non-inflammatary exudations. We noticed a significant decrease of CD1c ${ }^{+}$ myeloid and $\mathrm{CD}_{303}{ }^{+}$plasmacytoid dendritic cells in the peripheral blood of children with JIA. This seems to be due to migration of DCs to inflamed joints, where they mature and stimulate autoimmune response.

Dendritic cells could be the main population of leukocytes responsible for induction and prolongation of local inflammatory response. In synovial fluid, we also confirmed the presence of CD206/CD209 double positive cells which could represent a population of macrophages with DCs-like morphology. Interestingly, we found that the decrease in circulating myeloid DCs was highest in patients with systemic JIA. The percentage of CD1 $\mathrm{c}^{+} / \mathrm{CD} 19^{-}$cells was almost three times lower in patients with sJIA then in other subtypes of juvenile idiopathic arthritis.

\section{Acknowledgements}

The authors thank Barbara Baran M.Sc. for her technical contribution in sample preparation. They acknowledge Krzysztof Gaweda MD, PhD (Dept. of Orthopedics, Medical University of Lublin, Poland) and Jacek Walawski MD, PhD (Ortomix, Lublin, Poland) for their help in collecting post-traumatic SF, 
as well as Michal Latalski MD, PhD (Dept. of Pediatric Orthopedics, Medical University of Lublin, Poland) and Robert Piekarski MD, PhD (Dept. of Endocrinology and Neurology, Medical University of Lublin, Poland) for their contribution in collecting PB samples from control group children. We also thank all the patients and volunteers for participating in the study.

\section{References}

1. Lebre MC, Tak PP. Acta dendritic cell subsets: their roles in rheumatoid arthritis. Reumatol Port. 2008;33:35-45.

2. Rutella S, De Cristofaro R, Ferraccioli G. Function and dysfunction of dendritic cells in autoimmune rheumatic diseases. Hum Immunol. 2009;70:360-373.

3. Hart DN. Dendritic cells: unique leukocyte populations which control the primary immune response. Blood 1997;90:3245$-3287$.

4. Dzionek A, Fuchs A, Schmidt P et al. BDCA-2, BDCA-3, and BDCA-4: three markers for distinct subsets of dendritic cells in human peripheral blood. J Immunol. 2000;165:6037-6046.

5. Lebre MC, Tak PP. Dendritic cells in rheumatoid arthritis Which subset should be used as a tool to induce tolerance? Hum Immunol. 2009;70:321-324.

6. Dannecker GE, Quartier P. Juvenile idiopathic arthritis: classification, clinical presentation and current treatments. Horm Res. 2009;72(Suppl 1):4-12.

7. Kahn P. Juvenile idiopathic arthritis - current and future therapies. Bull NYU Hosp Jt Dis. 2009;67:291-302.

8. Page G, Miossec P. RANK and RANKL expression as markers of dendritic cell-T cell interactions in paired samples of rheumatoid synovium and lymph nodes. Arthritis Rheum. 2005;52:2307-2312

9. Page G, Chevrel G, Miossec P. Anatomic localization of immature and mature dendritic cell subsets in dermatomyositis and polymyositis: Interaction with chemokines and Th1 cytokine-producing cells. Arthritis Rheum. 2004;50:199-208.

10. Page G, Lebecque S, Miossec P. Anatomic localization of immature and mature dendritic cells in an ectopic lymphoid organ: correlation with selective chemokine expression in rheumatoid synovium. J Immunol. 2002;168:5333-5341.

11. Van Krinks CH, Matyszak MK, Gaston JS. Characterization of plasmacytoid dendritic cells in inflammatory arthritis synovial fluid. Rheumatology (Oxford). 2004;43:453-460.

12. Kavousanaki M, Makrigiannakis A, Boumpas D, Verginis P. Novel role of plasmacytoid dendritic cells in humans: induction of interleukin-10-producing Treg cells by plasmacytoid dendritic cells in patients with rheumatoid arthritis responding to therapy. Arthritis Rheum. 2010;62:53-63.

13. Lebre MC, Jongbloed SL, Tas SW, Smeets TJ, McInnes IB, Tak PP. Rheumatoid arthritis synovium contains two subsets of CD83-DC-LAMP-dendritic cells with distinct cytokine profiles. Am J Pathol. 2008;172:940-950.

14. Jongbloed SL, Lebre MC, Fraser AR et al. Enumeration and phenotypical analysis of distinct dendritic cell subsets in psoriatic arthritis and rheumatoid arthritis. Arthritis Res Ther. 2006;8:R15.

15. Cavanagh LL, Boyce A, Smith L et al. Rheumatoid arthritis synovium contains plasmacytoid dendritic cells. Arthritis Res Ther. 2005;7:R230-240.

16. Smolewska E, Stańczyk J, Brózik H et al. Distribution and clinical significance of blood dendritic cells in children with juvenile idiopathic arthritis. Ann Rheum Dis. 2008;67:762-768.
17. Smolewska E, Cebula B, Brózik H, Stańczyk J. Relationship between impaired apoptosis of lymphocytes and distribution of dendritic cells in peripheral blood and synovial fluid of children with juvenile idiopathic arthritis. Arch Immunol Ther Exp (Warsz). 2008;56:283-289.

18. Richez C, Schaeverbeke T, Dumoulin C, Dehais J, Moreau JF, Blanco P. Myeloid dendritic cells correlate with clinical response, whereas plasmacytoid dendritic cells impact autoantibody development in rheumatoid arthritis patients treated with infliximab. Arthritis Res Ther. 2009;11:R100.

19. Lim DS, Kang MS, Jeong JA, Bae YS. Semi-mature DC are immunogenic and not tolerogenic when inoculated at a high dose in collagen-induced arthritic mice. Eur J Immunol. 2009;39:1334-1343.

20. Jongbloed SL, Benson RA, Nickdel MB, Garside P, McInnes IB, Brewer JM. Plasmacytoid dendritic cells regulate breach of self-tolerance in autoimmune arthritis. J Immunol. 2009;182:963-968.

21. Yamazaki S, Inaba K, Tarbell KV, Steinman RM. Dendritic cells expand antigen-specific Foxp $3^{+} \mathrm{CD} 25^{+} \mathrm{CD} 4^{+}$regulatory T cells including suppressors of alloreactivity. Immunol Rev. 2006;212:314-329.

22. Steinbrink K, Mahnke K, Grabbe S, Enk AH, Jonuleit H. Myeloid dendritic cell: from sentinel of immunity to key player of peripheral tolerance? Hum Immunol. 2009;70: 289-293.

23. Yamazaki S, Steinman RM. Dendritic cells as controllers of antigen-specific Foxp $3^{+}$regulatory T cells. J Dermatol Sci. 2009;54:69-75.

24. Sidhu M, Griffiths MM, Bradley DS. Vaccination with collagen-pulsed dendritic cells prevents the onset and reduces the disease severity in the mouse model of spontaneous polychondritis. Clin Exp Immunol. 2009;157:350-358.

25. Vastert SJ, Kuis W, Grom AA. Systemic JIA: new developments in the understanding of the pathophysiology and therapy. Best Pract Res Clin Rheumatol. 2009;23:655-664.

26. Macaubas C, Nguyen K, Deshpande C et al. Distribution of circulating cells in systemic juvenile idiopathic arthritis across disease activity states. Clin Immunol. 2010;134:206-216.

27. Lechmann M, Berchtold S, Hauber J, Steinkasserer A. CD83 on dendritic cells: more than just a marker for maturation. Trends Immunol. 2002;23:273-275.

28. Cauli A, Pitzalis C, Yanni G, Awad M, Panayi GS. CD1 expression in psoriatic and rheumatoid arthritis. Rheumatology (Oxford). 2000;39:666-673.

29. Baeten D, Kruithof E, De Rycke L et al. Infiltration of the synovial membrane with macrophage subsets and polymorphonuclear cells reflects global disease activity in spondyloarthropathy. Arthritis Res Ther. 2005;7:R359-369.

30. Highton J, Kean A, Hessian PA, Thomson J, Rietveld J, Hart DN. Cells expressing dendritic cell markers are present in the rheumatoid nodule. J Rheumatol. 2000;27:339-346.

31. Hock BD, O'Donnell JL, Taylor K et al. Levels of the soluble forms of CD80, CD86, and CD83 are elevated in the synovial fluid of rheumatoid arthritis patients. Tissue Antigens. 2006;67:57-60.

32. Rivollier A, Mazzorana M, Tebib J et al. Immature dendritic cell transdifferentiation into osteoclasts: a novel pathway sustained by the rheumatoid arthritis microenvironment. Blood. 2004;104:4029-4037.

33. Lakey RL, Morgan TG, Rowan AD, Isaacs JD, Cawston TE, Hilkens CM. A novel paradigm for dendritic cells as effectors of cartilage destruction. Rheumatology (Oxford). 2009;48:502-507.

34. Wojas K, Tabarkiewicz J, Rolinski J. In vitro generation of dendritic cells from peripheral blood monocytes with recombined 
cytokines and natural stimulators. Centr. Eur. J. Immunol. 2002;27(Suppl. 1):142.

35. Saito I, Koshino T, Nakashima K, Uesugi M, Saito T. Increased cellular infiltrate in inflammatory synovia of osteoarthritic knees. Osteoarthritis Cartilage. 2002;10:156-162.

36. Laborde EA, Vanzulli S, Beigier-Bompadre M et al. Immune complexes inhibit differentiation, maturation, and function of human monocyte-derived dendritic cells. J Immunol. 2007;179:673-681.

37. Zhang R, Becnel L, Li M, Chen C, Yao Q. C-reactive protein impairs human $\mathrm{CD} 14^{+}$monocyte-derived dendritic cell differentiation, maturation and function. Eur J Immunol. 2006;36:2993-3006.

38. Puliti M, Bistoni F, Tissi L. Lack of B7-1 and B7-2 costimulatory molecules modulates the severity of group B Streptococcus-induced arthritis. Microbes Infect. 2010;12:302-308.

39. Bhatia S, Edidin M, Almo SC, Nathenson SG. B7-1 and B7-2: similar costimulatory ligands with different biochemical, oligomeric and signaling properties. Immunol Lett. 2006;104:70-75.
40. Ortiz M, Kaessmann H, Zhang K et al. The evolutionary history of the CD209 (DC-SIGN) family in humans and nonhuman primates. Genes Immun. 2008;9:483-492.

41. Dieguez-Gonzalez R, Akar S, Calaza M et al. Lack of association with rheumatoid arthritis of selected polymorphisms in four candidate genes: CFH, CD209, eotaxin-3, and MHC2TA. J Rheumatol. 2009;36:1590-1595.

42. Granelli-Piperno A, Pritsker A, Pack M et al. Dendritic cell-specific intercellular adhesion molecule 3-grabbing nonintegrin/CD209 is abundant on macrophages in the normal human lymph node and is not required for dendritic cell stimulation of the mixed leukocyte reaction. J Immunol. 2005;175: $4265-4273$.

43. Sturge J, Todd SK, Kogianni G, McCarthy A, Isacke CM. Mannose receptor regulation of macrophage cell migration. J Leukoc Biol. 2007;82:585-593.

44. Ochoa MT, Loncaric A, Krutzik SR, Becker TC, Modlin RL. Dermal dendritic cells comprise two distinct populations: CD1+ dendritic cells and CD209+ macrophages. J Invest Dermatol. 2008;128:2225-2231.

Submitted: 20 June, 2010 Accepted after reviews: 21 November, 2010 